\title{
La naturaleza en/de la ciudad
}

\author{
The nature in/of the city
}

<Resumen>

El diálogo naturaleza y ciudad ha convocado la atención, en estas últimas décadas, de científicos de las más variadas disciplinas

El gran impulso parte del desarrollo de una conciencia ambiental, por parte de la población en general, que se involucra reclamando mejores condiciones de vida.

Como profesionales, he aquí nuestro compromiso

$<$ Abstract $>$

Over the past decades, the dialogue between nature and the city has attracted the attention of scientists from the most varied disciplines. This major impetus stems from the development of environmental awareness among the general population that has become involved, demanding better living conditions.

As professionals, this is our commitment

<PALABRAS CLAVE>

PAISAJE / NATURALEZA / CIUDAD / AMBiEnTE / ECOLOGÍA

\section{<KEYWORDS>}

LANDSCAPE / NATURE / CITY / EN IRONMENT / ECOLOGY

\section{Introducción y presentación del tema}

Estas reflexiones sobre la naturaleza y la ciudad las presentaremos analizando el borde costero sobre el Río de la Plata, de nuestra ciudad, Montevideo, capital de la República Oriental del Uruguay. Limitaremos su estudio a los $25 \mathrm{~km}$ de costa más densamente urbanizada, desde la Bahía de Montevideo al Arroyo Carrasco.

El borde del río, ancho como mar, alterna playas en arco de blancas arenas con tramos y puntas rocosas, siendo el paisaje urbano identificatorio y referencial de la ciudad.

Todo el tramo considerado tiene declaración de Monumento Histórico Nacional.
La costa montevideana es el gran atractivo, para sus habitantes y para los turistas. El diálogo arquitectura y naturaleza, con todas las carencias y errores, que después marcaremos, es un escenario que tiene un gran poder de convocatoria para el tiempo de ocio, para todas las franjas etarias y sin exclusiones de clase social.

Nuestro estudio puede enmarcarse siguiendo la investigación realizada en el Instituto de Urbanismo (ITU), de la Facultad de Arquitectura (UDELAR) y publicada como «Transformaciones socioterritoriales del Área Metropolitana de Montevideo».

Según el trabajo mencionado, el Área Metropolitana de Montevideo, está «(...) ubicada en el litoral Sur de Uruguay con más

\footnotetext{
* Arquitecta uruguaya. Recibe su título de Arquitecta en la Facultad de Arquitectura del Uruguay en 1963. Desde 1986 inicia una línea de investigación, nueva en el país, la de los Espacios Abiertos Públicos de la ciudad, en especial los ajardinados y sus técnicos actuantes. Es miembro de la Unión Latinoamericana de Paisaje (ULAP) y miembro fundador y actual Presidenta de la Asociación Uruguaya de Arquitectura de Paisajes (AUDADP), afiliada a IFLA. Actualmente es Miembro Votante por Uruguay del Comité Científico Internacional de Paisajes Culturales ICOMOS/IFLA. Es también Coordinadora para América Latina del Comité de Paisajes Culturales de IFLA.
} 
de $100 \mathrm{~km}$ de costas sobre el Río de la Plata, ocupa una extensión territorial de 2.500 km² y concentra el $57 \%$ de la poblacional total del país. Se localiza en jurisdicción de tres de los 19 departamentos (unidades políticoadministrativas) que conforman el territorio nacional. Incluye la totalidad del Departamento de Montevideo, sede de la ciudad del mismo nombre y capital del país, más de la mitad del territorio del Departamento de Canelones y la porción Sureste del Departamento de San José».

El itinerario costero partiendo desde la entrada a la Bahía, recorre la fachada marítima de la Ciudad Vieja y los Barrios Sur y Palermo. Sigue por el Parque Rodó y la Playa Ramírez, dejando del lado del Río de la Plata, la Punta Brava con su farola, y del otro lado el Barrio de Punta Carretas.

Avanzando hacia el Este, el Barrio Pocitos y su playa en arco. Seguimos por el Puerto de Yates del Buceo y su pequeña playa. Llegamos al Barrio de Malvín y su playa. Luego un destacado mojón topográfico, la Punta Gorda, totalmente urbanizado. Terminamos con el Barrio de Carrasco y su amplia playa hasta el Arroyo Carrasco.

En muchos tramos se avanzó sobre las dunas, ignorando que la arena es un recurso natural finito. Situación irreversible hoy, donde hay más conocimientos al respecto y aumenta la conciencia ambiental para el estudio de la ciudad.

Debido a los fuerte vientos que azotan durante todo el año la costa montevideana, el Pampero que viene del Sur y la Sudestada, que como su nombre lo indica azota la ciudad desde el Sureste, aunque se dan zonas fuertemente ajardinadas, las especies vegetales que resisten ese particular microclima no son muchas, por lo que el recorrido por el paseo marítimo está caracterizado por palmeras, en especial las criollas yatay (Butia yatay) y el ombú (Phitolaca dioca) y las exóticas Phoenix canariensis y Washingtonia. La Playa de Carrasco tiene un gran tramo fuertemente caracterizado por espesas plantaciones de tamarices (Tamarix).

El tema presentado en este artículo lo hemos tratado especialmente en el "Seminario Paisaje - Cultura - Sociedad (Sep-Dic 2007)" dictado en el Instituto Universitario BIOS, para la Maestría de Diseño de Paisaje. Es el resultado de trabajos de investigación comenzados en la Facultad de Arquitectura estatal y luego continuados con el apoyo de instituciones privadas.

Rambla sur (fotografía del autor)

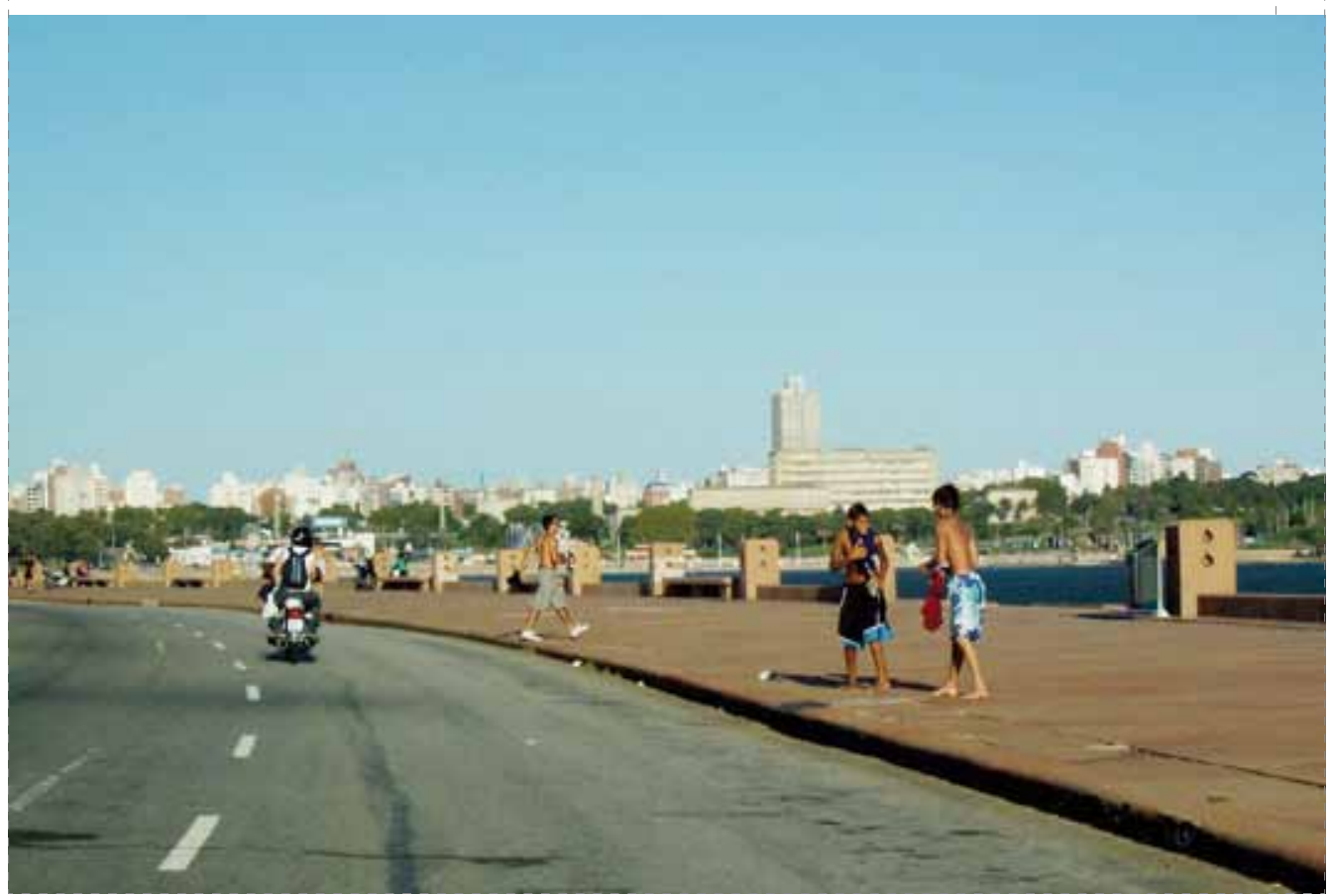

\section{Definiciones y conceptos}

Entendemos el concepto de naturaleza como un constructo cultural, de donde «la naturaleza en/de la ciudad» se refiere a la relación sociedad y naturaleza materializada en la ciudad. Sus llenos y sus vacíos, su arquitectura y sus espacios libres.

Se considera naturaleza y cultura como dos de las palabras más complejas. En su origen eran conceptos diferentes, pero no por eso opuestos. Naturaleza, en latín evoca nacimiento y cultura, transformación. Así llegamos a la transformación de la naturaleza por la cultura.

Las investigaciones de Anne Whiston Spirn, publicadas por la Universidad de Cambridge (EE.UU.), nos proponen ideas radicales cuando escribe: las ciudades son parte de la naturaleza. $Y$ además afirma que los mismos procesos naturales que operan en lo que se llama «naturaleza», lo hacen en la ciudad.

La naturaleza en la ciudad es mucho más que el verde, es el aire que respiramos, la tierra que pisamos, el agua que bebemos y expedimos y los organismos con los cuales compartimos nuestro hábitat.

Hasta hace poco la forma urbana y la arquitectura se estudiaban como resultado de una sociedad y una cultura, en las cuales la naturaleza desempeñaba un papel poco importante, excepto por el aporte del elemento vegetal.

Todo hábitat humano altera la geografía original, en una palabra todos los factores abióticos; clima, atmósfera, agua y suelo. Pero también los factores bióticos son alterados; la flora y la fauna del lugar. Los edificios crean una nueva topografía, un nuevo perfil del terreno y la pavimentación una nueva superficie. La flora y la fauna original se adaptan a estas nuevas condiciones 0 desaparecen.

Con respecto al concepto de paisaje, consideramos que; superando los criterios estéticos con los cuales se calificaban los paisajes en el siglo xIx, citamos a Fernando González Bernáldez cuando afirma que «[...] paisaje es toda información que el hombre recibe de su entorno».

El paisaje por lo tanto es un hecho cultural, de carácter perceptivo, habrá tantos paisajes como observadores consideremos. También varios observadores pueden, y de hecho es lo común, coincidir en sus apreciaciones con respecto a determinados paisajes, de donde éstos podrán ser clasificados por su valor social.

El paisaje será percibido por todos los sentidos; la vista, el oído, el tacto, el olfato y el gusto y 
con toda la complejidad biológica del hombre que lo percibe, considerando sus estados emocionales y afectivos, su cultura y su educación.

De esta manera podemos hablar de «paisaje visual», de "paisaje sonoro» o de «paisaje olfativo». También de "paisaje emocional» que cambiará según los estados de ánimo del observador, según las estaciones del año, de acuerdo a la luz diurna o nocturna.

Definimos brevemente el ambiente como el resultado de las recíprocas relaciones del hombre, agrupado en sociedad, y la naturaleza, en un lugar geográfico dado y en un tiempo histórico determinado.

El profesor Joaquín Sabaté Bel, en el «Seminario de Paisajes Culturales» (Jun 2005, Buenos Aires), afirmaba que el término «paisaje cultural» estaba en los escritos de historiadores y geógrafos, alemanes y franceses, ya hacía finales del siglo XIX. Y entre otros importantes investigadores citaba a Carl Sauer, de la Universidad de Berkeley, quien hacia 1920, hizo importantes aportes a este concepto.

La aceptación de la naturaleza en la ciudad está todavía en función de un conjunto predeterminado de valores estéticos, aunque desde los años '70 comienzan a conocerse las investigaciones de lan McHarg, «diseñando con la naturaleza», y la obra de sus seguidores, proponiendo la necesidad de un cambio de valores.

Los valores del diseño urbano y arquitectónico han ido a la deriva durante demasiado tiempo, dictados por las convenciones estéticas. E problema radica en que el diseño urbano debe adecuarse a los procesos naturales, de sol y sombra, vientos, Iluvias, frío y calor, los cambios estaciónales, etcétera.

El hombre cree dominar la naturaleza, pero es ésta la que le impone limitaciones. La naturaleza es una realidad omnipresente.

\section{Estudio de caso: El Paseo} Marítimo, la «Rambla», de Montevideo al borde del Río de la Plata

La ciudad de Montevideo se funda respondiendo a los intereses imperialistas de los reyes de Castilla y Aragón, atendiendo a una geografía que abrigaba el mejor puerto natural del Río de la Plata, la llave de la conquista de tierras hacia el interior de inmenso continente americano.

Por desacuerdos políticos y económicos con la ciudad de Buenos Aires, ciudad-puerto que quería mantener su hegemonía en el Plata, recién cuando el avance portugués se hace evidente se funda la ciudad, en 1726, por razones estratégico-militares.

Desatendiendo las mínimas necesidades del hábitat humano, los ingenieros y topógrafos militares, ubican el centro poblado en la península rocosa, que podía custodiar la entrada al puerto, pero sin agua dulce ni bosques para leña y sin amparo para el azote de los fuertes vientos.

Se desconocieron las condiciones ambientales preexistentes y ahí comenzó para el europeo conquistador, la lucha por la supervivencia. La necesidad de buscar un equilibrio, inestable, entre ciudad y naturaleza. El agua dulce tenía que ser repartida en la ciudad por los aguateros y la leña, imprescindible para cocinar los alimentos, se encontraba, a $5 \mathrm{~km}$, en los bordes del Arroyo Miguelete.

Los primeros pobladores y luego las lavanderas negras esclavas y los inmigrantes pobres, recorrían kilómetros para encontrar pozos de

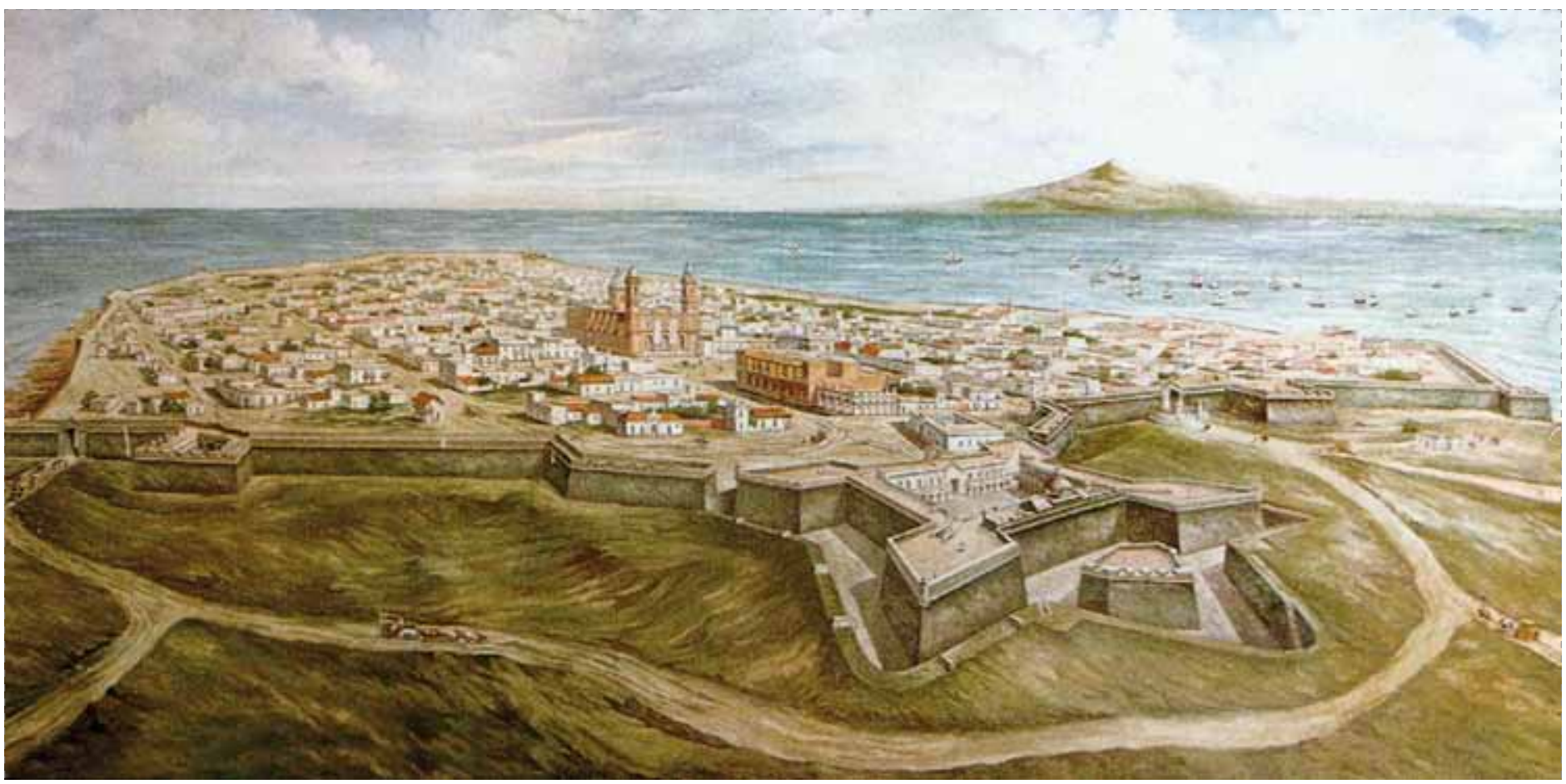

Vista de Montevideo, óleo de C. Menck Freire (fuente: Museo Histórico Nacional). 
agua dulce donde lavar la ropa. Y cuando la ciudad se extendía, más lejos tenían que ir.

El mar siempre ha ejercido un gran atractivo para el hombre, por su belleza intrínseca, o por su misterio, de ahí llegaba lo nuevo, lo desconocido; bueno o malo.

El borde costero es el encuentro de dos ecosistemas: la tierra, medio relativamente estable y el agua, medio inestable, inseguro, siempre en movimiento, siempre cambiante.

El hombre americano nómada, que recorría estos territorios, lo hacía en función de una geografía amable, de praderas suavemente onduladas, de clima sin temperaturas extremas, con buenos cursos de agua, donde podía encontrar alimento y abrigo fácilmente.

El hombre blanco europeo, que llegó a estas tierras, percibió un paisaje diferente del europeo. Darwin lo expuso claramente, se asombró de la falta de árboles, que sólo se daban en el borde de los ríos y arroyos, pero no en la costa del Río de la Plata, donde las dunas alternaban con las rocas.

La naturaleza había sido muy poco alterada por los pueblos aborígenes y no ofrecían al europeo los recursos naturales que ellos codiciaban, metales y piedras preciosas; fue el conquistador quien introduciendo en estas tierras de praderas naturales, el ganado vacuno y caballar, nos dio nuestra riqueza, pero alteró fuertemente los ecosistemas preexistentes y el paisaje.

Las visuales hacia el Río de la Plata, ancho como mar, y los campos de horizontes lejanos acostumbraron, al europeo y luego al criollo a una geografía con escasos mojones naturales, a aguzar la percepción del paisaje hasta el utópico horizonte, para integrarse a la naturaleza circundante.

Montevideo, proviene su nombre de la única elevación significativa de la costa. Cuentan las crónicas de viajeros, que el nombre tiene su origen en las palabras de un marinero portugués, quien al avistar el Cerro, de 150 m de altura, exclamó: «monte vide eu!». La geografía liderando el paisaje, como también el nombre del país, República Oriental del Uruguay, que hace referencia a la nación al Este del Río Uruguay.

El Cerro de Montevideo es un fuerte mojón geográfico, el cual puede verse desde varios puntos de la ciudad y se ha constituido en nuestro «belvedere». No es casual que aparezca en el escudo de la ciudad y en el escudo nacional.

Calle Río Negro; al fondo el Río de la Plata (fotografía del autor)

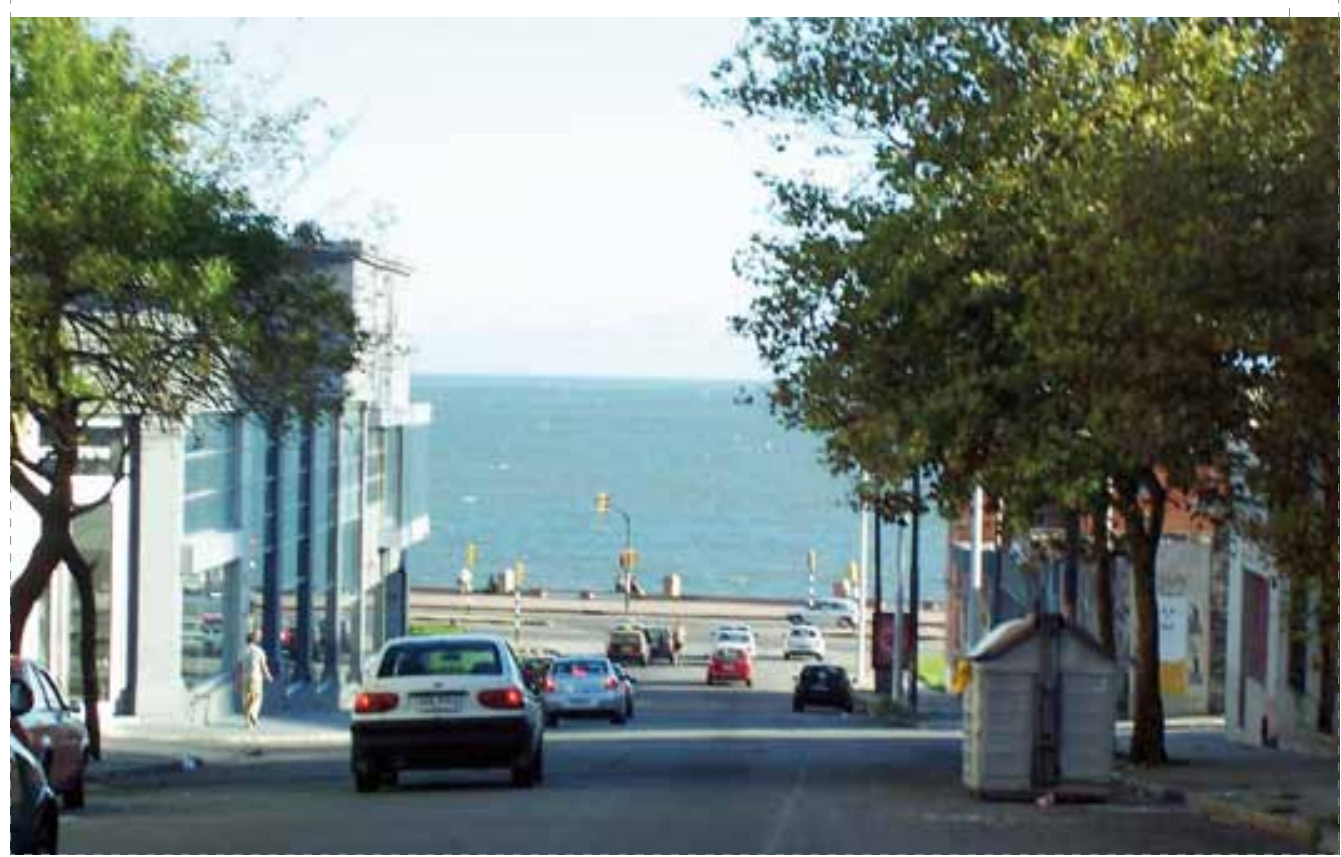

La ciudad colonial amurallada, cortaba la relación visual entre el hombre y el río, pero siempre se posibilitaron vistas hacia el exterior, ya sea por los lugares donde se accedía a la zonas de baños, como la estrecha conexión con el puerto.

En 1829 se decreta el derribo de las murallas, proceso que tomó varias décadas. Fue entonces cuando las perspectivas, hacia el río - hacia la bahía, desde la plaza fundacional y por calles y esquinas, caracterizaron el paisaje urbano de la ciudad, ahora capital de un país independiente.

Para el Plan de Ensanche de la Ciudad Vieja, hacía la Ciudad Nueva, de 1830 , se aplica, en ciertos aspectos, un criterio ecológico, con la calle principal, hoy 18 de Julio, eje de la Nueva Ciudad que se acopla a la calle Sarandí de la Ciudad Vieja, corriendo ambas sobre el lomo de la cuchilla.

Las calles transversales desaguando hacia la bahía o hacia el río, respetaron la topografía del sitio. El fondo marítimo se percibe, enmarcado por la arquitectura y los árboles.

La línea del horizonte marítimo es un privilegiado patrimonio natural.

Si primero la ciudad creció hacia el Norte, ocupando las antiguas chacras, desde las primeras décadas del siglo xx, lo hizo hacia el Este siguiendo el borde del río e instalándose arriesgadamente sobre las dunas movedizas.
En ambos casos sólo se tuvo en cuenta la belleza escenográfica de las tierras que se iban urbanizando. Atendiendo también a condicionantes higienistas, primero fue buscar «los aires puros del campo» y luego «los beneficios de los baños de mar».

Pero la relación con el río siempre fue muy fuerte. Hacia 1873 ya había instalaciones balnearias en dos playas cercanas al casco histórico, Pocitos y Ramírez, a las cuales llegó rápidamente la extensión de la ciudad y pasaron a ser barrios costeros.

Partiendo de la Bahía de Montevideo, hacia el Este, en 1928 , se realiza el $1^{\text {er }}$ tramo del paseo marítimo, conocido como la Rambla Sur. Era parte de un Plan Vial, proyectado y realizado desde la municipalidad montevideana por ingenieros viales, con el único objetivo de establecer rápidas conexiones entre los barrios alejados y el Centro de la ciudad. Así se realizaron los primeros 5 kilómetros.

Para la concreción de este audaz proyecto, se ganaron tierras al mar y se expropiaron y demolieron casi 1.000 inmuebles, un barrio de "prostitutas y gente de mal vivir», los «bajos fondos», como se los llamaba por entonces, hecho aplaudido por la prensa y las clases medias y altas montevideanas.

Pero otros lamentaban el antiguo Barrio Sur que se iba. Lo recuerda el tango «Sur», compuesto por Ramón Collazo y Victor Soliño, estrenado en las fiestas carnavaleras de 1930 
Sombras arrojadas; Playa Pocitos (fotografía del autor)

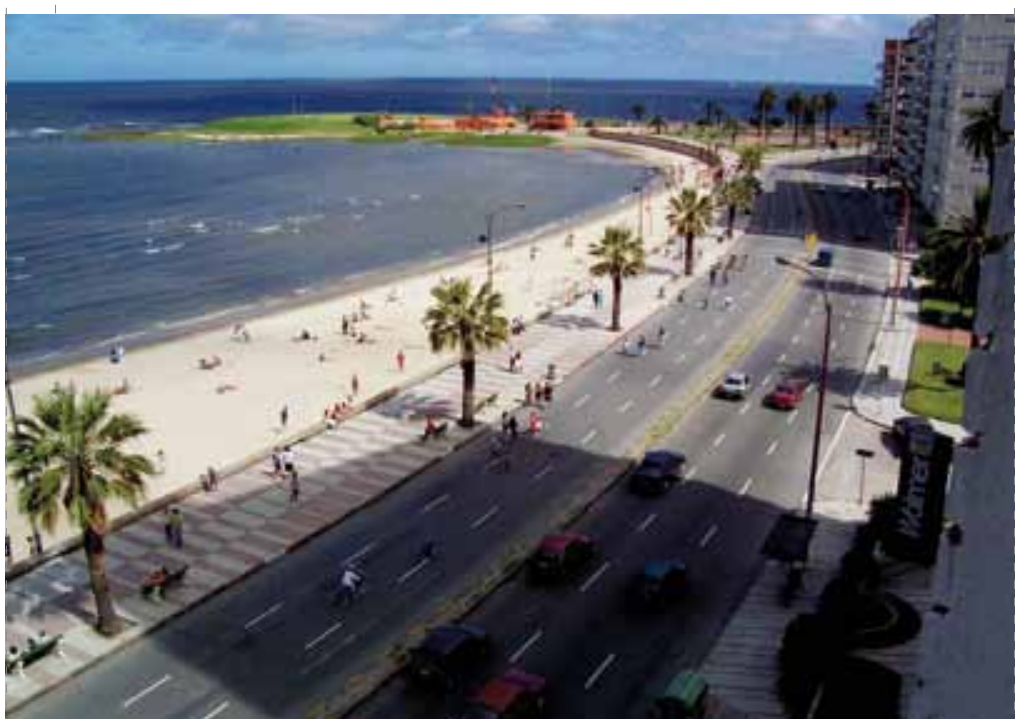

Arco iris hacia el Puerto de yates del Buceo (fotografía del autor)

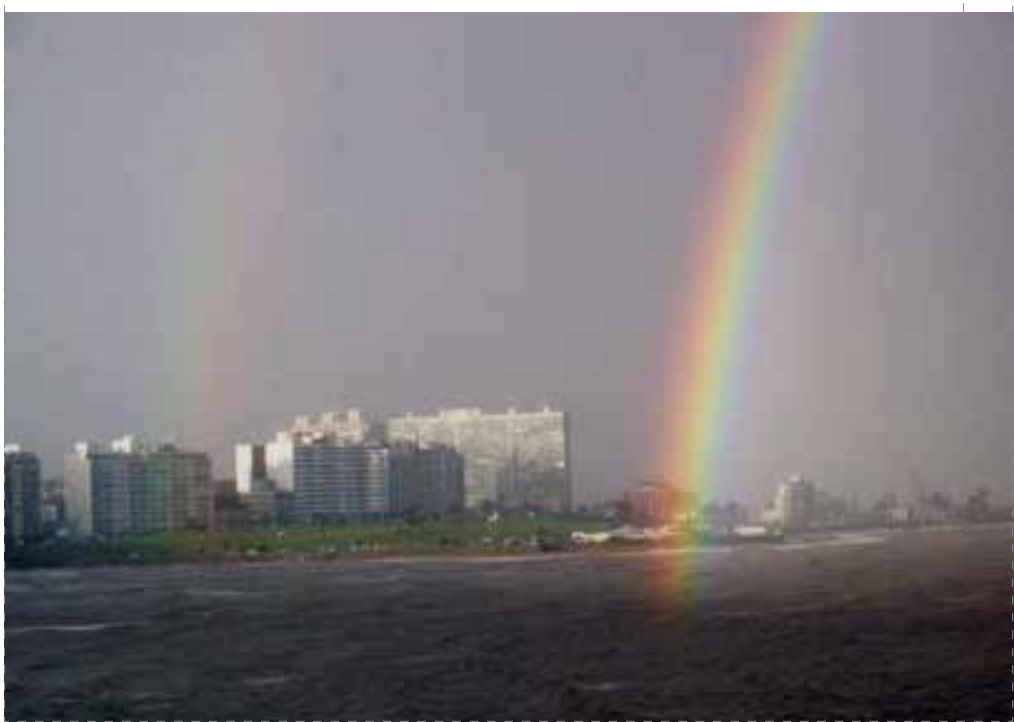

y hasta hoy muy recordado: "Barrio Sur, viejo y querido,/que te van arrancando a pedazos (...) en la calle ruinosa y desierta/sopla un viento de desolación/viejo barrio que te vas/te doy mi último adiós/ya no te veré más/».

Otros edificios fueron respetados y hoy son mojones urbanos importantes del paisaje costero, como, por ejemplo, el dique Mauá y la Cía. del Gas por el cual se desvió la Rambla, dejándolos del lado del río y un viejo gasómetro, el cual en 1985 fue motivo para que dos pintores uruguayos, lo transformaran en cilíndrica pintura mural a escala urbana.

La franja peatonal fue pavimentada con granito nacional, de color rosado y también los asientos que la acompañan. Dos grandes terrazas, también de granito rosado, nos acercan al nivel del río. El color rosado del granito se impone junto al gris azulado del río.

Del otro lado de la franja vehicular, frente a la fachada arquitecturizada, se construyeron en un tramo, hacia 1940, estupendos jardines, diseñados por el arquitecto Juan Scasso, funcionario municipal, con dos fuentes de diseño contemporáneo, de granito rosado también. La mejor obra paisajística de la primera mitad del siglo xx.

Hoy, estos jardines son historia, no se ha respetado su diseño original y se ha perdido la unidad del planteo original, sustituyéndose por diversificados y muy mediocres representantes de los espacios urbanos de fines del siglo pasado.

Si nos hemos detenido más en la Rambla Sur es porque consideramos que escritores, artistas plásticos y músicos han contribuido a crear un imaginario colectivo, una «magia» de la Rambla Sur y sus barrios, donde nació el candombe y el tango. Lo que no sucede con los otros barrios de la costa.

La Rambla fue rápidamente continuándose, pero ya no en granito. Siguiendo el contorno del borde natural, unas veces en arco, otras veces en puntas salientes, Ilega hasta el arroyo Carrasco hacia 1950, uniendo barrios, balnearios, puertos de recreo y de pescadores.

Carrasco, tiene características muy diferentes a los Barrios Sur y Palermo. Nació en 1912 cuando las «clases altas», desde el punto de vista socioeconómico, deciden alejarse y tener su balneario exclusivo, para disfrutar los meses estivales.

Arquitectura y jardines fueron pensados en función de los meses de verano. Había que evitar que el sol entrara a las habitaciones, lo cual era una ventaja, pues quedando el río al Sur se tenía la posibilidad de disfrutar de él como escenario.

A partir de 1950, cuando Carrasco se convirtió en un barrio más de la ciudad, y sus viviendas de uso temporal, se transformaron en permanentes, la orientación de sus locales no era la más adecuada para los meses invernales. No hubo cambios arquitectónicos importantes y los recambios, como por demás en toda la ciudad, atendían más el reclamo inmobiliario de vistas al paseo marítimo, que a condicionantes de ecología urbana.

La estupenda zona de barrancas de piedra de la Punta Gorda, es cada vez más agredida, no respetándose la topografía original, excavándola, tanto para edificios en altura, como para viviendas individuales, para incluir garajes y zonas de servicio y no pasarse de las alturas que las ordenanzas municipales indican.

Las ordenanzas municipales, no han sido muy oportunas en la consideración de la naturaleza y la arquitectura edilicia. Para la mayor parte de la ciudad, se permite una altura máxima de diez pisos, incluido el borde costero, de donde el perfil urbano es una línea continua en muchos tramos, perdiéndose cada vez más las «ventanas» que permitían ver el otro perfil, detrás de la «fachada costera».

Con estas ordenanzas, y los loteamientos permitidos la mayor parte de ellos realizados por agrimensores y no urbanistas, las calles que desembocan al río, entre los altos edificios, se han transformado en verdaderos corredores de viento, siendo, muchos días al año, muy dificultoso caminar por ellas.

También con este frente costero de continua arquitectura, como el río queda, en general al Sur de la ciudad, algunas playas, por ejemplo Pocitos que es una de las más concurridas, en tempranas horas de la tarde empieza a tener grandes zonas de sombra arrojada por los edificios, tanto en invierno como en verano.

El hombre, en su arrogancia, pretende imponerse a la naturaleza, y cambiarla pero ésta sigue presente; el sol, la lluvia, el viento. Naturaleza y ciudad construyen, en un permanente fluir de interacciones, el paisaje cultural urbano. 


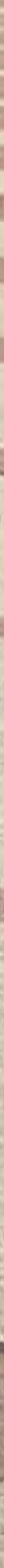




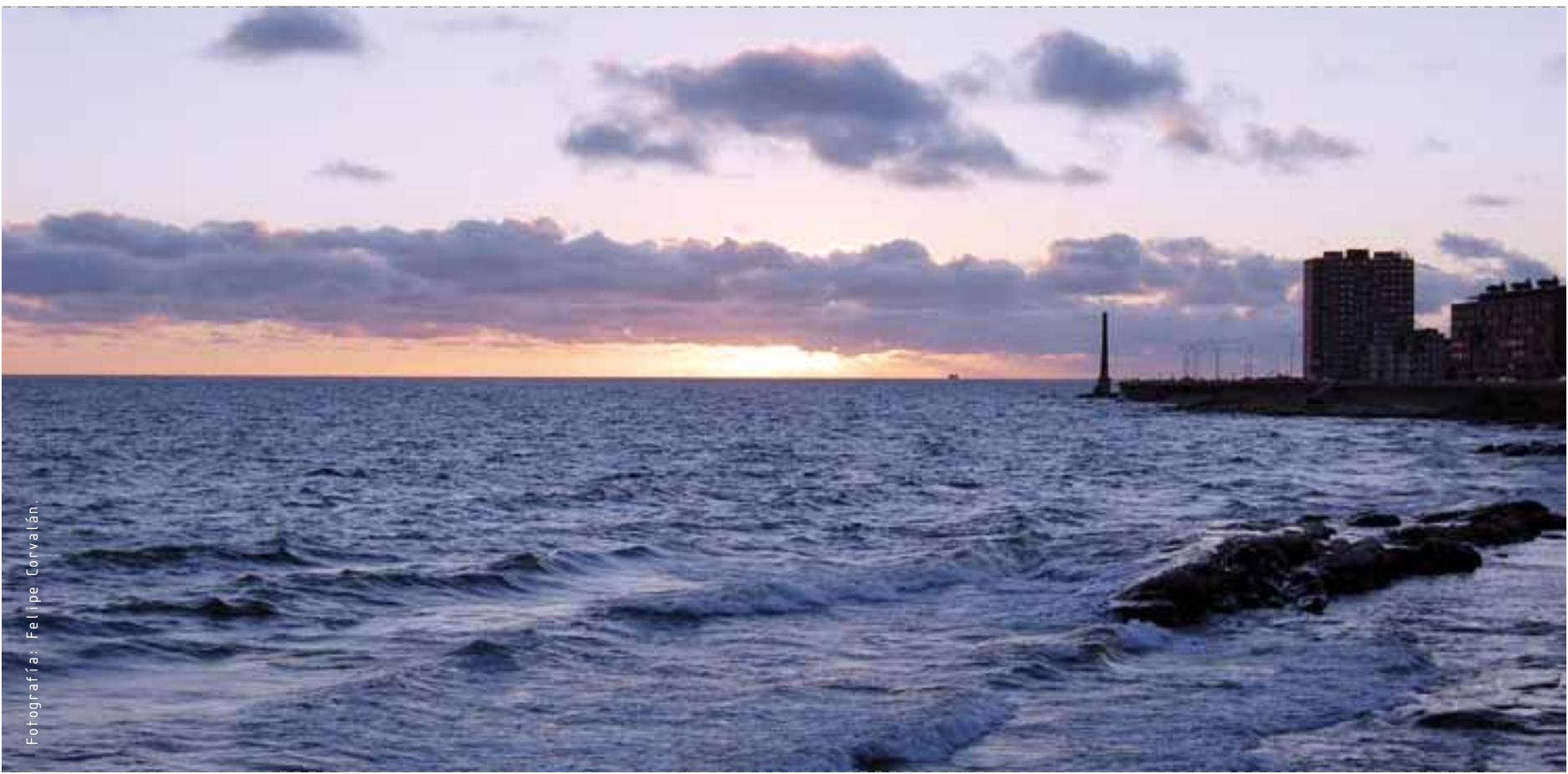

\section{Paisaje cultural urbano}

Finalmente llegamos a presentar la naturaleza y la ciudad con un único concepto, el paisaje cultural urbano.

Le debemos la conceptualización actual del término «paisaje cultural» como «[...] propiedades culturales que representan el trabajo continuado de la naturaleza y el hombre»., al resultado de largas e intensas series de encuentros de expertos internacionales, analizando el tema desde el punto de vista patrimonial.

El Prof. Léon Pressouyre de la Universidad de París, escribía en El Correo de la UNESCO del año 2000: «[...] la desaparición progresiva de las barreras que separan el patrimonio cultural y natural, y una mayor atención a los valores del patrimonio inmaterial, maltratados y fragilizados por la mundialización [...]» conforman «[...] un patrimonio común e indivisible, en el que se tiene plenamente en cuenta la interacción del hombre y la naturaleza, idea que va sustituyendo, poco a poco, en nuestra mente a ese otro patrimonio fragmentado [...]» que hemos defendido hasta ahora.

En mi opinión lo afirmado por estos especialistas, puede aplicarse a todos los paisajes culturales, ya sean patrimoniales o no. Debo aclarar que este nuevo enfoque de paisaje cultural, tiene sus defensores y sus opositores, lo cual quizás lo haga más interesante el plantearlo en esta ocasión.

Las diferencias provienen desde que profesión académica se considere; los arquitectos, los urbanistas, los paisajistas, los geógrafos, los historiadores, los gestores del ordenamiento territorial y muchos otros, tienen opiniones discordantes y en continua discusión.

Defiendo la posición que desde el Paisaje, es la manera holística de analizar la ciudad y su territorio -la naturaleza, el paisaje, la arquitectura y el hábitat- con un enfoque ambiental.

\section{Conclusiones}

La consideración de la naturaleza, el paisaje y la arquitectura en el ambiente urbano, con el objetivo de lograr mejor calidad de vida para la sociedad involucrada, es un gran desafío, que debemos enfrentar considerando un gran universo de ideas, sin dejar de lado a ninguna ciencia o disciplina científica que pueda aportarnos para lograr nuestro objetivo y considerando como muy acertada la frase de convocatoria para esta revista: «paisaje como escenario de las interacciones sociales y consolidación de la conciencia ambiental».

\section{Bibliografía}

- Artigas, Chabalgoity, García, Medina, Trinchitella. Transformaciones socioterritoriales del Área Metropolitana de Montevideo. Revista Eure 2002; XXVIII(85).

- Bernardo González Bernáldez. Ecología y paisaje. Madrid: Editorial Blume, 1983.

- Kevin Lynch. La imagen de la ciudad. La Habana: S/N, 1970

- Michel Hough. Naturaleza y ciudad. Editorial Gustavo Gili, 1998.

- Margarita Montañez. Al rescate de la plaza. E rol de la plaza en la sociedad urbana del siglo xxl. Multiversidad franciscana de América Latina. Montevideo, 2000.

- Margarita Montañez. «La ciudad analizada a través de sus espacios abiertos públicos». En: Clases magistrales de profesores extranjeros. Maestría de Gestión del Ambiente, el Paisaje y el Patrimonio. Universidad Nacional del Nordeste, Facultad de Arquitectura y Urbanismo, 2006 (editoras: Sonia Beriman y Ángela Sánchez Negrette).

- Margarita Montañez. «La Rambla Sur de Montevideo». Cuadernos de la Facultad de Arquitectura. Montevideo, 1981.

- lan McHarg. «Disegn with nature». Natural History Press NY 1992.

- Anne Whiston. 0 jardim de granito. $1^{\text {ra }}$ ed Universidad de Cambridge (en inglés), 1983.

- Anne Whiston. The language of landscape. Thomson-Shore Inc, 1998. 